\title{
Sex difference in spatial distribution of the big-clawed shrew Sorex unguiculatus
}

\author{
Tadayuki INOUE
}

\begin{abstract}
Inoue T. 1991. Sex difference in spatial distribution of the big-clawed shrew Sorex unguiculatus. Acta theriol. 36: $229-237$.

Population density and spatial distribution of overwintered (mature) individuals in the big-clawed shrew Sorex unguiculatus (Dobson, 1890) were investigated by mark-recapture over five year period $(1983$ - 1987). Density did not vary widely from year to year. Females usually had smaller and more stable home ranges than males. Home range overlap between males was much larger than that between females. The number of females whose home ranges overlapped with that of a male $(\mathrm{NFOM})$ ranged 0 to $6($ mean $=2.65)$. The sex difference in the use of space appeared to due to different reproductive activity. Female territorial behaviour can be attributed to the need to secure food resources and hence to increase offspring survival, whereas the larger home ranges of males could allow access to several receptive females.

Institute of Applied Zoology, Faculty of Agriculture, Hokkaido University, Sapporo, 060, Japan

Key words: spatial distribution, sex difference, Sorex unguiculatus, functional significance
\end{abstract}

\section{Introduction}

Soricine shrews are distributed widely over the Northern Hemisphere. The ecology and behaviour of shrews must have an important influence on terrestrial ecosystem in these regions. However, there is still little information about social organization and social behaviour of shrews.

One of the important characteristics of the spatial distribution of soricine shrews is that territorial behaviour occurs before sexual maturity (Croin Michielsen 1966, Buckner 1966, 1969; Platt 1976, Hawes 1977, Pernetta 1977, Ellenbroek 1980, Inoue 1988, see also Barnard 1984). However, data on spatial distribution and reproductive behaviour of sexually mature individuals is scarce (but see Shillito 1963, Croin Michielsen 1966, Hawes 1977). Spatial distribution and use of space appears to be associated directly with reproductive and mating activities. Hence, it is predicted that spatial distribution differs between mature males and females.

In this paper, I examine spatial distribution of sexually mature individuals in the big-clawed shrew Sorex unguiculatus (Dobson, 1890) and discuss the functional significance of sex difference in their use of space. 


\section{Study area and methods}

\section{Study area}

This study was undertaken in a rectangular section of deciduous broad-leaved forest located at Naganuma, Sorachi district, Hokkaido, Japan. An area surrounded by wheat fields on three sides was selected for the present survey (Fig. 1). The study area and surrounding areas was partitioned by a watercourse one meter in width. The rectangular area was divided into two sub areas - site A $(45 \mathrm{~m} \times 40 \mathrm{~m}, 0.18$ ha) and site B (110 $\mathrm{m} \times 40 \mathrm{~m}, 0.44 \mathrm{ha}$ ). The border between the two areas (broken line in Fig. 1) was partitioned off with zinc plates ( $80 \mathrm{~cm}$ high) buried $30 \mathrm{~cm}$ deep in the ground (see also Inoue 1988).

The dominant tree species in the study area were Alnus hirsura and Sambucus sieboldina. The dominant ground cover consisted of Solidago alitissima, Artemisia montana, Cirsium kamtschaticum, Hosta rectifolia, Polygonum thunbergii and Carex spp.

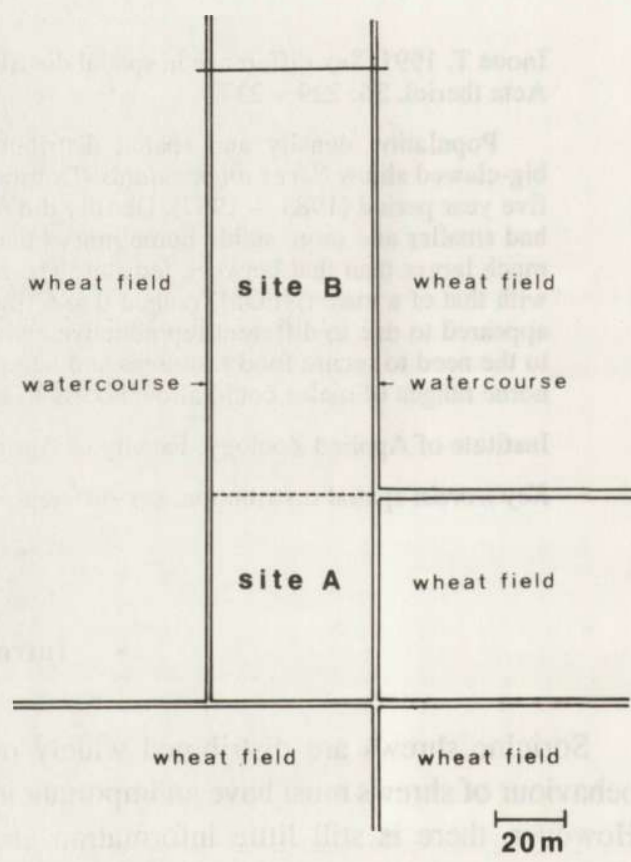

\section{Trapping procedures}

The survey was conducted over a period of five years from 1983 to 1987. The survey on site B, however, started later in 1985. Population censuses were generally carried out twice a month from April to November (1983), October (1984), September $(1985,1986)$ or July (1987). One census period lasted generally for five or six consecutive days, except for occasional interruptions caused by heavy rain. However, to obtain data on the change in condition of females and to obtain accurate density estimates in young, census duration was increased to 15 and 20 census days in May and June, respectively. Traps without bait were set at 16:00 or 18:00 hours and examined at 2-hour intervals in $4-6$ patrols every night. By this procedure, only two shrews were killed accidentally.

Trapping was carried out using pitfall traps $(14 \mathrm{~cm}$ diameter and $27 \mathrm{~cm}$ depth). Forty two $(6 \times 7)$ traps in Site A and $65(5 \times 13)$ traps in Site B were set at approximately $7 \mathrm{~m}$ and $9 \mathrm{~m}$ intervals, respectively. These trapping sites was not always fixed. When a shrew was trapped, trapping sites were moved to a new site within a circular area of $2 \mathrm{~m}$ in a diameter from the initial point of capture. This $2 \mathrm{~m}$ circle area was regarded as a single trapping site see also Inoue 1988). 
Shrews were individually marked by toe-clipping at first capture. The trap site, weight, age class, reproductive condition and sex of the shrew were recorded at each capture. The shrew captured were divided into two age classes, i.e. "overwintered" and "young". Overwintered shrews are heavier and have tails with worn, short hairs, whereas young shrews are characterized by light bodies and well-haired tails. The sex of overwintered shrews are easily distinguishable.

To assess the relationship between philopatric offspring and its mother, experimental manipulations were made in Site B. Five overwintered females (July 1985) and eight young (July 1986) were removed. In this paper, the trapping data concerning these individuals before their removals only was included.

\section{Data analysis}

The following indices used for describing spatial distribution of individuals were calculated for each shrew with at least 3 captures within a one month period:

(1) Observed range length (ORL): All positions at which a certain animals was captured within one month were plotted, and the longest distance between capture points was regarded as the observed range length (Stickel 1954).

(2) Distance between centres of activity (DCA): In order to show the monthly shift of the shrew's home range, the geometric centre of all positions of each shrew was calculated and regarded as the "centre of activity" as defined by Hayne (1949). The distance between centres of activity of sequential months was then measured.

(3) Degree of home range overlap (DHO) and number of female home ranges overlapping that of a male (NFOM): The home range was estimated monthly by the minimum area method (Mohr 1947, Stickel 1954). DHO to neighbouring individuals was as:

$$
\mathrm{DHO}=1 / 2 \times(\mathrm{No} / \mathrm{Na}+\mathrm{No} / \mathrm{Nb})
$$

where $\mathrm{No}$ is the size of overlapped area of shrew a and b, $\mathrm{Na}$ and $\mathrm{Nb}$ are home range sizes of shrew a and b, respectively. In this study, two individuals whose home ranges bordered each other were regarded as neighbouring individuals. NFOM for a certain male indicates number of females having overlapping home ranges to that male.

\section{Estimation of parturition of females}

To evaluate the reproductive season of females, parturition dates were estimated from data on body weight and development of nipples. The increase in body weight over time of a particular female was regarded as the advancement of her pregnancy, and thus it is considered that her parturition occurred when her weight declined.

A typical example of temporal change in weight and condition of nipples of a certain female was represented. The individual was first captured on 23 April 1984. Thereafter, the increase in body weight was recorded, reaching a peak at $13.8 \mathrm{~g}$ on May 6 . Rapid decline in weight occurred after this date. This decline seems to have been due to parturition. This was confirmed by the condition of her nipples following the decline in weight. Thus, by using data on temporal changes in female's weight, the female's parturition date was estimated as follows:

$$
\text { EST }(\text { Estimate of Parturition Date })=(T a+T b) / 2
$$

where $T a$ is capture date at which decline in body weight occurred and $T b$ is capture date at which the heaviest weight were recorded. Any remaining fraction after $T a+T b$ was divided by 2 was disregarded.

\section{Results}

\section{Basic life history}

No young attained sexual maturity in their year of birth. They showed no external features of both testicular bulges in the genital region for males and prominent nipples for females. However, as the testicular bulges of all overwintered males were observed in April of their 
second year, they may have attained sexual maturity by spring in their second year. Furthermore, as overwintered females first developed nipples from around May or June in each year and also as their offspring were captured from late May (Inoue 1988), it is assumed that females do not reproduce until spring in their second year.

A few were captured as late as November in their second year (1983), but none survived through to the following spring.

\section{Population density of mature individuals}

Table 1 shows both the number of mature individuals in the study area and population density. An increase in the number after 1984 was due to an expansion in size of the study area. Annual variation in male and female density was small. Male and female densities reached peak respectively at 1.55 and 1.50 times their minimum. When data were totalled over the five years, the sex ration of mature individuals was not significantly different from 50:50 ratio ( $G$-test, $G=2.109, n=107$, n.s.). At least $57.0 \%$ of shrews ( 61 out of 107 ) settled in the study area.

\section{Reproductive ecology of mature females}

A total of 79 parturitions were observed over a period of five years. Out of 61 females, 59 $(96.5 \%)$ gave birth at least once in their second year. Twenty (33.8\%) females gave birth twice. No female gave birth more than three times.

Table 1. Population number and density of overwintered individuals during five years. Recruits are defined as individuals which were newly captured in spring in their second year. Residents are individuals which were captured in the study area in their first year.

\begin{tabular}{|c|c|c|c|c|c|c|c|c|}
\hline \multirow{2}{*}{ Year } & \multicolumn{4}{|c|}{ Female } & \multicolumn{4}{|c|}{ Male } \\
\hline & $\mathrm{N}$ & Recruits & Residents & N/ha & $\mathrm{N}$ & Recruits & Residents & $\mathrm{N} / \mathrm{ha}$ \\
\hline 1983 & 4 & - & - & 22.2 & 4 & - & - & 22.2 \\
\hline 1984 & 4 & 1 & 3 & 22.2 & 4 & 1 & 3 & 22.2 \\
\hline 1985 & 18 & 1 & 5 & 33.3 & 9 & 1 & 2 & 16.7 \\
\hline 1986 & 19 & 6 & 13 & 30.6 & 13 & 3 & 10 & 21.0 \\
\hline 1987 & 16 & 3 & 13 & 25.8 & 16 & 4 & 12 & 25.8 \\
\hline Total & 61 & 11 & 34 & - & 46 & 9 & 27 & - \\
\hline
\end{tabular}

Table 2. Temporal distribution of female's parturition dates from 1983 to 1987.

\begin{tabular}{|c|c|c|c|c|c|c|c|}
\hline \multirow{2}{*}{ Year } & \multicolumn{7}{|c|}{ Month (N) } \\
\hline & Apr. & May & Jun. & Jul. & Aug. & Sep. & Oct. \\
\hline 1983 & 1 & 3 & 0 & 2 & 2 & 0 & 0 \\
\hline 1984 & 0 & 4 & 0 & 1 & 0 & 0 & 0 \\
\hline 1985 & 2 & 13 & 1 & 2 & 1 & 0 & - \\
\hline 1986 & 2 & 16 & 1 & 3 & 9 & 0 & - \\
\hline 1987 & 4 & 11 & 1 & 0 & - & - & - \\
\hline Total & 9 & 47 & 3 & 8 & 12 & 0 & 0 \\
\hline
\end{tabular}


Table 2 shows temporal distribution in dates of parturition. Of all the parturitions observed, $59(74.9 \%)$ occurred between April and June. First parturitions occurred from April 23 to June 10. All Parturitions observed after June were the female's second litter of the year. No parturitions were found after August. These results indicate that female's parturition occurs mainly before June. If the gestation period can be assumed to be similar to that in the related species, Sorex araneus, 20 - 28 days (Dehnel 1952, Vogel 1972), then the conception of first litters occurred from late March to late May.

\section{Sex difference in spatial distribution}

When the average values of ORL between neighbouring months were compared, only two out of 38 ( 18 for males and 20 for females) $(5.3 \%)$ showed significant changes. Because the monthly changes of ORL for both sexes were insignificant, monthly values for each year were averaged. The values of ORL in males were larger than those in females in every year (Fig. 2).

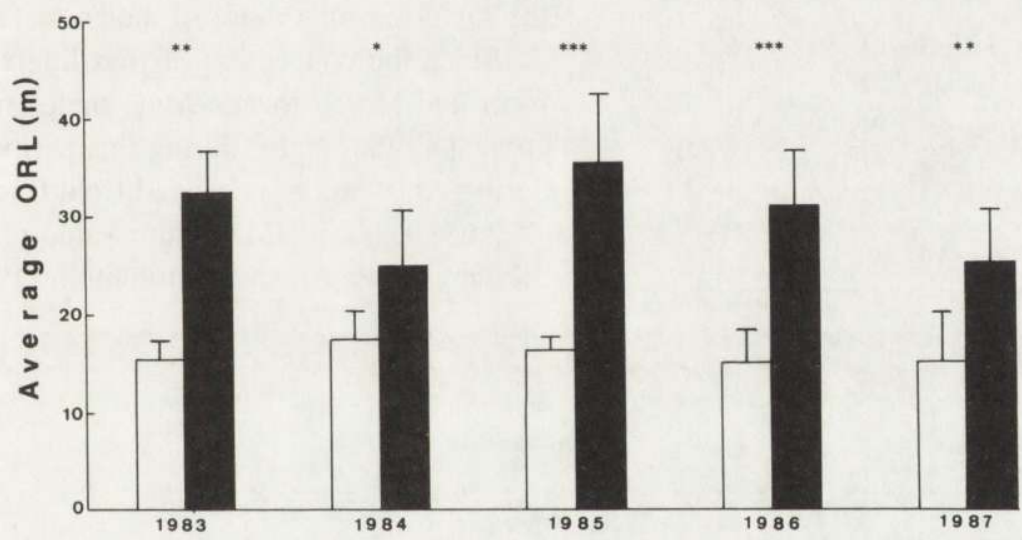

1.ig. 2. Annual changes of average observed range length (ORL, mean \pm SD) for females ( $\square$ ) and males ( $)$ ) from 1983 to 1987. Significance level in Mann Whitney $U$ tests is indicated as * $=p<0.05, * *=p<0.01$, and $* * *=p<0.001$.

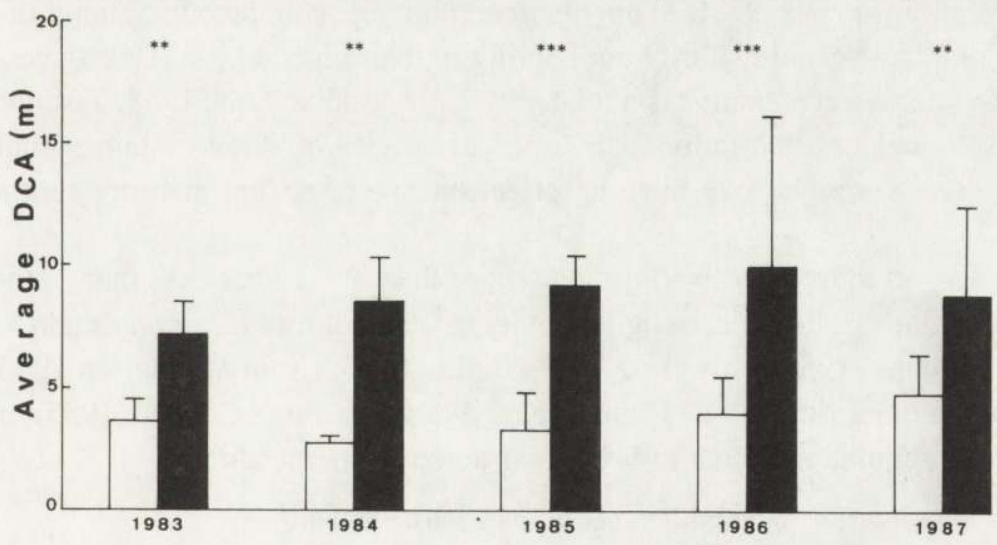

I.ïg. 3. Annual changes of average distance between centres of activity (DCA, mean \pm SD) for females ( $\square$ ) and males ( ) from 1983 to 1987. Significance level in Mann-Whitney $U$ tests is indicated as $* *=p<0.01$, and $* * *=p<0.001$. 
When values of DCA between neighbouring periods were compared, three out of 28 (13 for males and 15 for females) (10.7\%) showed significant changes. As the changes was slight, all DCA values for each year were averaged. The mean values of DCA for males were larger than those for females every year (Fig. 3). These results indicate that home ranges of females were smaller and more immobile than those of males and that sex differences in spatial distribution do not vary widely between different years.

When data from a 5 year period were

Table 3. Mean value of number of females whose home ranges overlapped with that a male (NFOM) in April and May during five years. The value in parentheses indicates the range of NFOM.

\begin{tabular}{lcc}
\hline Year & NFOM & Sample size, N \\
\hline 1983 & $1.75(1-2)$ & 4 \\
1984 & $1.80(0-3)$ & 4 \\
1985 & $4.22(3-6)$ & 9 \\
1986 & $2.75(1-4)$ & 13 \\
1987 & $2.19(1-4)$ & 16 \\
'83-'87 & $2.65(0-6)$ & 46 \\
\hline
\end{tabular}
combined, DHO between males (mean \pm SD, $0.25 \pm 0.27, n=84)$ was significantly greater than that between females $(0.03 \pm 0.09, n=20)$ (Mann-Whitney $U$ test, $U=261.5, z=4.772, p$ $<0.00003)$. This indicates that home ranges of females were more exclusive of conspecifics of the same-sex than those of males.

Since the conception of first litters occurred from late March to late May, males must have copulated with mates during this period. NFOM during April and May ranged from 0 to 6 (mean $=2.65$, Table 3 ). Maximum value (1985) was 2.4 times higher than the minimum (1983).

\section{Discussion}

Basic life history

Although a representative of the genus Sorex species have been reported to attain sexual maturity in their first year (review in Jeanmaire-Besançon 1988, see also Rudd 1955, Johnston and Rudd 1957, Baird et al. 1978), S. unguiculatus did not reproduce in autumn of their first year and did not attain sexual maturity until spring in their second year. This agrees with Abe (1968). Because this S. unguiculatus is a relatively large soricine (Abe 1968, Yoshino and Abe 1984), this result suggests that individuals in larger species of shrews attain sexual maturity later and hence body weight may have an effect on age of sexual maturity (but see Pucek 1960).

In this species, no individual lived through more than one winters. As many other authors have reported similar results concerning longevity in other shrews ( $S$. araneus and $S$. minutus, Brambell 1935, Dehnel 1952, Crowcroft 1957, Shillito 1963, Croin Michielsen 1966, Pernetta 1977, Grainger and Fairley 1978, Churchfield 1980; S. vagrans, Rudd 1955), maximum longevity in wild population seems to be similar among soricine shrews.

\section{Sex difference in spatial distribution}

Pronounced sex differences in spatial distribution of sexually mature individuals were observed. These differences could be due to different reproductive and mating activities 
between the two sexes. This section looks at the functional significance of sex differences in spatial distribution.

Females exhibit non-overlapping home ranges toward same-sexed conspecifics. This could be attributable to several important functions of females in this species (see also Cantoni and Vogel 1989). First, because pregnant and lactating females show increased energy demands (Gittleman and Thompson 1988, Genoud and Vogel 1990), it is necessary for them to secure sufficient food supply. Female territorial behaviour forces them to reserve adequate supply of food resources through their exclusive space use. Further, since females had more immobile ranges than males, this also suggests that it is advantageous for females to facilitate acquisition of food resources through familiarity with their range sites (see Greenwood 1980).

Secondly, territorial behaviour of females may be attributed to the need to secure food and space for their offspring after weaning. In this species, some offspring remained in their natal area (T. Inoue, unpubl.). Since philopatric offspring could settle their territories without the risk of dispersal behaviour and gain the acquisition for food resources, it is advantageous for them to have a territory overlapping their mother's.

Thirdly, territorial behaviour of females may be attributed to avoidance of infanticide by other females and males. Crowcroft (1957) reported when the lactating female with newborn offspring and a male were kept in the same cage, the male entered her nest and killed some young. Thus, in wild populations, females might protect their litters against strange intruders through their range defense.

Two phenomena indicate that male's spatial distribution may depend on their mating behaviour. Firstly, males had larger home range sizes during their mating season than females and occupied ranges which included several females. Space use by males might be related to access to females or their home ranges. Because oestrus of females lasts for less than one day in related species (S. araneus, Brambell 1935, Dehnel 1952, Crowcroft 1957; Blarina brevicauda, Pearson 1944), it could be advantageous for males to have ranges adjacent (or overlapping) the female's territory (Hawes 1977) which would mean maintaining larger ranges than females.

Secondly, the home range of males was more mobile than that of females. In captivity, females of related species (S. araneus) display aggressive behaviour toward invading males except at the period of their oestrus (Crowcroft 1957). This suggests that males are not permitted to share the nest with females or to guard the females as a mate in close proximity. If so, it could be advantageous for males to move in order to search for potential mates rather than to guard particular female(s) against other males (see also Searle 1990).

Studies on spatial distribution in other species of shrews also report that mature females occupy and defend smaller home ranges and males have home ranges covering those of several females (Croin Michielsen 1966, Platt 1976, Hawes 1977). In conclusion, this study suggests that the sex differences of shrews are directly associated with different reproductive and mating activities between the two sexes; female's territorial behaviour is attributed to securing food resources through their range defense, whereas male's larger home ranges seem to facilitate access to several reproductive females.

Acknowledgement: I thank Y. Saito for his constructive comment on the manuscript. 


\section{References}

Abe H. 1968. Classification and biology of Japanese Insectivora (Mammalia). 2. Biological aspects. J. Fac. Agr. Hokkaido Univ. 55: $429-458$.

Baird D. D., Timm R. M. and Nordquist G. E. 1983. Reproduction in the Arctic shrew, Sorex arcticus. J. Mammal. 64: 298 - 301.

Barnard C. J. 1984. Shrews. [In: The encyclopedia of mammals 1. D. W. Macdonald, ed.]. George and Unwin, London: $758-763$.

Brambell F. W. R. 1935. Reproduction in the common shrew (Sorex araneus Linnaeus). Phil. Trans. Roy. Soc. Lond., B. 225: $1-62$.

Buckner C. H. 1966. Populations and ecological relationships of shrews in tamarack bogs of southeastern Manitoba. J. Mammal. 47: 181 - 194.

Buckner C. H. 1969. Some aspects of the population ecology of the common shrew, Sorex araneus, near Oxford, England. J. Mammal. 50: $326-332$.

Cantoni D. and Vogel P. 1989. Social organization and mating system of free-ranging, greater white-toothed shrews, Crocidura russula. Anim. Behav. 38: $205-214$.

Churchfield S. 1980. Population dynamics and the seasonal fluctuations in numbers of the common shrew in Britain. Acta theriol. 25: $415-424$.

Croin Michielsen M. C. 1966. Intraspecific and interspecific competition in shrews Sorex araneus L. and Sorex minutus L. Archs. Néerl. Zool. 17: 73 - 174.

Crowcroft P. 1957. The life of the shrew, Reinhardt, London: $1-166$.

Dehnel A. 1952. The biology of breeding of common shrew, Sorex araneus L. in laboratory conditions. Annls Univ. M. Curie-Skłodowska, Sect. C 6: 359 - 376. [In Polish with English summary]

Ellenbroek F. J. M. 1980. Interspecific competition in the shrews Sorex araneus and Sorex minutus (Soricidae, Insectivora): a population study of the Irish pygmy shrew. J. Zool., Lond. 192: 119 - 136.

Genoud M. and Vogel P. 1990. Energy requirements during reproduction and reproductive effort in shrews (Soricidae). J. Zool., Lond. 220: $41-60$.

Gittleman J. L. and Thompson S. D. 1988. Energy allocation in mammalian reproduction. Am. Zool. 28: $863-875$.

Grainger J. P. and Fairley J. S. 1978. Studies on the biology of the pygmy shrew, Sorex minutus, in the west of Ireland. J. Zool., Lond. 186: 109 - 141.

Greenwood P. J. 1980. Mating system, philopatry, and dispersal in birds and mammals. Anim. Behav. 28: $1140-1162$

Hawes M. L. 1977. Home range, territoriality and ecological separation in sympatric shrews, Sorex vagrans and Sorex obscurus. J. Mammal. 58: 354 - 367.

Hayne D. W. 1949. Calculation of size of home range. J. Mammal. 30: 1- 18.

Inoue T. 1988. Territory establishment of young big-clawed shrew, Sorex unguiculatus (Dobson) (Insectivora, Soricidae) Res. Pop. Ecol. 30: 83 - 93.

Jeanmaire-Besançon F. 1988. Sexual maturity of Crocidura russula (Insectivora: Soricidae). Acta theriol. 33: $477-485$.

Johnston R. F. and Rudd R. L. 1957. Breeding of the salt marsh shrew. J. Mammal. 38: 157 - 163.

Mohr C. O. 1947. Tables of equivalent population of north American small mammals. Am. Midl. Nat. 37: $223-249$.

Pearson O. P. 1944. Reproduction in the shrew (Blarina brevicauda Say). Am. J. Anat. 75: 39 - 93.

Pernetta J. C. 1977. Population ecology of British shrews in grassland. Acta theriol. 22: 279-296.

Platt W. J. 1976. The social organization and territoriality of short-tailed shrew (Blarina brevicauda) populations in old-fields habitats. Anim. Behav. 24: 305 - 318 .

Pucek Z. 1960. Seasonal maturation and variability of the reproductive system in young shrew (Sorex L.) in the first calender year of life. Acta theriol. 3: 269 - 296.

Rudd R. L. 1955. Age, sex, weight comparison in three species of shrews. J. Mammal. 36: $323-339$. 
Searle J. B. 1990. Evidence for multiple paternity in the common shrew (Sorex araneus). J. Mammal. 71: $139-144$.

Shillito J. F. 1963. Field observations on the growth, reproduction and activity of a woodland populations of the common shrew, Sorex araneus. Proc. zool. Soc. Lond. 140: 99 - 114.

Stickel L. F. 1954. A comparison of certain methods of measuring ranges of small mammals. J. Mammal. 30: $399-411$

Vogel P. 1972. Beitrag zur Fortpflanzungsbiologie der Gattungen Sorex, Neomys und Crocidura (Soricidae). Verhandl. Naturf. Ges. Basel. 82: 165 - 192

Yoshino H. and Abe H. 1984. Comparative study on the foraging habits on two species of soricine shrews. Acta theriol. 29: $35-43$.

Received 15 April 1991, accepted 18 October 1991.

Acta Theriologica $36(3-4): 237-238,1991$.

BOOK REVIEW

Ecological risks

Ecological risks. Perspectives from Poland and the United States. W. Grodziński, E. B. Cowling and A. I. Breymeyer, eds. National Academy Press, Washington D. C. 1990. 415 pp. ISBN 0-309-04293-3 pk.

The science has changed during the last decade toward an acknowledge very high complexity of nature. We shall never be able to describe all the various components in our environment in detail. As the quantum mechanics set limitation for the accuracy of our observations in physics it does also in ecology. While the limitations in physics are caused by our influence on the object by the observation, the limitations in ecology is caused by the enormous complexity of nature (ecosystems).

These conclusions are very clear. The nature is complex, but we cannot observe all details; consequently we must attempt to get a more holistic view on our environment by including only the mainline and the bearing processes in this description. We must therefore put more emphasis on synthesizing our many analytical results. We cannot do science without analytical method, but we should not do entirely analysis; we need to stop from time to time in our analytical effort and make synthesizing conclusions. On of such synthesis is the reviewed book, based on the joint Polish - USA workshop on "Ecological Research and Environmental Protection" held in Mogilany near Kraków in 1987.

The various contributions to the book were developed to illustrate the current state of knowledge about ecological risks in Poland and the United States. It begins with an overview on natural systems for human beings and then define what is meant by ecosystems, ecological risk assessment, and ecological risk management. They point up some interesting contrasts and similarities between ecological goals and conditions in Poland and the United States. 